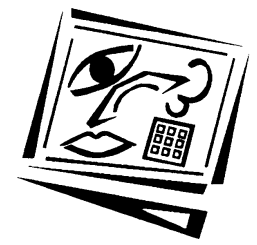

\title{
The impact of Chinese language lessons in a virtual world on university students' self-efficacy beliefs
}

\author{
Michael Henderson, Hui Huang, Scott Grant \\ Monash University \\ Lyn Henderson \\ James Cook University
}

\begin{abstract}
It was found in the two-year study reported in this article that a single collaborative language lesson using Second Life can result in a statistically significant increase in student self-efficacy beliefs across a range of specific and general language skills. However, students with different 'real life' prior experience varied in the durability of their language performance beliefs over time. A between-group analysis revealed differences in the pre- and post-tests, which is explained by the specificity of the curriculum - that is, the curriculum within the Second Life environment, and not just the environment itself, has a significant impact on student beliefs. This helps to dispel some critics' concerns about the pedagogical value of these environments. However, a within-group analysis revealed that students with infrequent experience of the 'real life' language context increased in their beliefs, while students with frequent experiences had similar initial responses to the other students, but were more varied in their responses over time. It is proposed that these variations over time are a result of an interaction between the domain specificity of the curriculum and authenticity, or in other words, salience of the enactive mastery experiences in Second Life with that of 'real life'.
\end{abstract}

\section{Introduction}

There is a growing body of literature around the educational advantages of virtual worlds. However, rigorous empirical research on the value of these environments in terms of measures of learner improvement, such as self-efficacy, continues to be scant. Self-efficacy can be summarised as the confidence in one's own abilities to achieve an outcome. It has been shown to be an important attitudinal variable influencing motivation, and consequently, a strong predictor of future achievement. Without this kind of data it may be easy for some critics to claim that "learning may be more lighthearted than pedagogical" (Bowers, Ragas \& Neely, 2009, p. 40). The issue here is not whether learning is occurring, but that it may not be of a type that is desirable or expected. Despite this criticism there is a continued investment in virtual worlds by educational institutions in Australasia including universities and an increasing number of language schools offering language learning courses conducted in part or wholly through virtual worlds.

This article reports on an ongoing study responding to the gap in knowledge at the nexus of virtual worlds, instructional design for language learning and self-efficacy beliefs. In particular, this quantitative study has investigated if a series of collaborative 
Chinese language lessons in Second Life could sustain or improve university students' self-efficacy beliefs about language performance. The lessons (tutorials) were held oncampus in a teaching room with a computer for each student, but were conducted in Second Life. The lessons under scrutiny were specifically focussed on Chinese language and culture content previously covered in the classroom and in the textbook. Students were expected to choose appropriate vocabulary and correct grammatical structures in a dynamic, semi-spontaneous scenario to communicate with fellow learners and the teachers to achieve the designated tasks.

The first year of data (Henderson, Huang, Grant \& Henderson, 2009) revealed a strong statistical significance $(p<.01, n=100)$ in the increase in self-efficacy beliefs about language performance with moderate $\left(e t a^{2}>0.06\right)$ to large $\left(e t a^{2}>0.14\right)$ effect sizes after only one lesson. However, several concerns were also reported (Henderson et al., 2009), such as resilience beyond the lesson, domain specificity and construct validity. As a result of the highly positive but potentially problematic findings, a further study of 81 students over two lessons was conducted and is the focus of this article. The findings offer additional insights, but also reinforce the fact that the relationship between Second Life lessons and self-efficacy beliefs is far from simple.

\section{Affordances of virtual worlds for language learning}

Virtual worlds such as Second Life are particularly well suited for teaching and learning second languages. Students can immerse themselves in linguistically appropriate environments (e.g. Chinese restaurant with Mandarin signs, menus, etc), adopt roles and even identities that can provide a rich affective and cognitive model for language performance, as well as interact and collaborate with others to achieve complex goals through pedagogically appropriate media such as text, voice and video. Second Life is able to support competency-based training in areas such as vocabulary and grammar like other computer-assisted language learning tools do, and in addition can also facilitate synchronous interaction between teachers, students and others, including native speakers, in rich, creative ways. A synthesis of the research literature spanning virtual worlds and language learning was conducted, the outcomes of which were coupled with the authors' experiences in teaching within virtual worlds to identify eight key affordances. These affordances are presented in Table 1.

Virtual worlds in second language acquisition and intercultural awareness require further research. Our understanding of the role of virtual worlds in language acquisition continues to be heavily based on text-based multi-user virtual environments such as MUDs and MOOs. However, virtual worlds add much more than visual and auditory media; they offer instructors and students greater choices for collaboration, learner autonomy, creativity and experimentation, including identity play and formation.

Virtual worlds are potentially valuable environments for learning a second language and for intercultural awareness. This study investigates the impact of a Second Life experience on students' self-efficacy beliefs. Measuring performative data, such as student knowledge of Chinese language in a pre- and post-test, can only tell us what the students have learnt. Self-efficacy, on the other hand, has been shown to be a strong predictor of future achievement. 
Table 1: Virtual world affordances for language learning

\begin{tabular}{|l|l|l}
\hline Affective & It is proposed that virtual presence can result in reduced apprehension and
\end{tabular} filter embarrassment that otherwise can impede experimentation such as through roleplaying. Sanchez (1996) notes this in relation to text-based virtual worlds, and it is supported by Schwienhorst (2002) in relation to graphically rich environments*. Moreover, Schwienhorst points out that role-play in this context "should not be misunderstood as role-playing as in 'at the train station' scenarios in some language classrooms but in the more fundamental sense of using alternative personas to approach potentially construct-altering situations" (p. 202). In face to face classroom environments, student language learning outcomes can suffer from what has been termed "foreign language classroom anxiety" (Backer, 1999; Horwitz, Horwitz \& Cope, 1986; Zhao \& Lai, 2009), particularly at the output stage (Hauck \& Hurd, 2005). This affective filter arises because of learner perception of a threatening environment in the form of negative feedback from classmates or the instructor, prompted by their attempt at producing output in the language being learnt. The use of virtual worlds for language learning has been shown to reduce such anxiety (Access to Virtual and Action Learning Live ONline, 2010; Hundsberger, 2009; Peterson, 2011; Rankin, McNeal, Shute \& Gooch, 2008).

Persistent Virtual worlds are persistent - that is, the environment (e.g. Chinese restaurant) and environ- $\quad$ the objects (e.g. Chinese menu) do not disappear at the end of the lesson, unless ments and programmed to do so. This is also true of records of activity, including transcripts of records text-based dialogue. Consequently, users can return to the place of their learning, interact with the objects and, depending on the instructional design, peruse records of the event (Bell, 2008). Schwienhorst (2002) argues that persistent records of interaction allow students to "critically examine their own performance, or rather, the performance of their virtual selves" (p. 202). This is further supported by Thorne (2008), who found that lingering utterances (on-screen or recalled via 'chat history') facilitated language learning and were also particularly valuable for use to provide individual learners with crucial feedback on their language performance.

Physical The immersive social environment of virtual worlds provides a range of discourse and ling- elements that are generally not available in less immersive environments. For uistic co- example, indexical language (here, this, etc) is often problematic in teleconferencing presence or other computer-mediated communications (Schwienhorst, 2002). Hence, the value of virtual worlds is that it merges the physical co-presence and linguistic co-presence of the interlocutors (Schwienhorst, 2002). Both types of co-presence are important elements in discourse, and facilitate learning through the negotiation of mutual knowledge (Clark \& Marshall, 1981). In addition, Dalgarno and Lee (2010) maintain that co-presence allows learners to "engage simultaneously in shared tasks and/or produce joint artefacts by operating on the same objects in real time", which can "pave the way for rich and truly collaborative experiences that foster positive interdependence within a learning group" (p. 22).

Avatar Students control their avatars to explore and interact, independent of the instructor. control While this autonomy is limited by software and environmental design, it does afford and student-centred learning. At the simplest level, students can form (or be directed to learner form) groups and collaborate in similar ways to classroom interactions. Unlike autonomy typical discussion forum or text chat learning environments, students can dynamically create and reshape groups according to pedagogical imperatives or interpersonal and social dynamics. Schwienhorst (2002) points out that the affordance of learner autonomy in supporting experimental, learner-centred environments can raise language and linguistic awareness and performability as well as support complex thinking and critical reflection. Collentine (2011) confirmed that there is a positive correlation between learner autonomy in 3D virtual environments and the linguistic complexity and accuracy of learner production.

The value It is proposed that virtual worlds such as Second Life can provide a contextually rich of text environment (e.g. with graphics, animation, audio and text stimuli) that can serve as interact- $\quad$ powerful cognitive aids to text-based interactions. Simply because Second Life can ions, even support voice does not mean that it is always the most appropriate medium for the 
in a virtual learning outcomes being targeted. Indeed, the research literature from language world education in general and computer-mediated language education in particular experience reveals that writing not only improves written language skills, but also facilitates orality as well as linguistic and metalinguistic awareness (Beauvois, 1998; Chun \& Plass, 2000; O'Rourke, 2005; Schwienhorst, 2002; Sykes, 2005; Thorne, 2008; Wells, 1981). Ma's (1996) research in text-based virtual worlds also revealed a greater level of self-disclosure, egalitarianism and intercultural awareness than found in face to face exchanges between East Asian and North American college students. For students learning character-based languages like Chinese, text-based interactions also provide the opportunity to consolidate knowledge of Hanyu pinyin romanisation and character recognition (Grant \& Clerehan, 2011).

Mediated Virtual worlds have the advantages of other simulations in that information can be environ- included and excluded as needed. The virtual world acts as a mediator of the ment sometimes overwhelmingly rich linguistic and cultural information that can be found in real life experiences. Aspects of that rich information can be decreased, omitted, enhanced, synthesised or otherwise changed to reduce learner cognitive load, heighten awareness and facilitate processing. However, extra information could also be included in new ways to enable learners to interrogate the environment and objects within it in ways that address their learning styles (e.g. auditory, kinetic, etc), preferences and other needs. For instance, street signs in a virtual environment can be clicked to reveal the pronunciation of the name of a road written in Chinese characters, unlike real life signs that remain mute. Flight announcements in a virtual airport can be linguistically authentic and simultaneously targeted in their content so as to meet the specific needs and levels of the task and learners. Careful design of the immersive social environment can reduce the need for the layer of abstract thinking required in textbook-based and other formal learning situations (Carr, 1995).

Context- $\quad$ Virtual worlds can interact in contextually appropriate ways with learners. For sensitive instance, learners can be greeted by a 'bot' whenever they enter a room (location interact- $\quad$ context), but that greeting can also be sensitive to an endless number of variables ions such as the time of day, the gender of the learner (or his/her avatar), the formality of context (e.g. the bot as teacher versus the bot as shop assistant) and the frequency of visits. An example of the implications for language learning is that context-specific variations in language can be vicariously experienced through the avatar.

Soundscapes also provide additional environmental scaffolding to learners by giving auditory clues about things such as a location that is important to the completion of a task, or simply provide greater fidelity in experience. Dalgarno and Lee (2010) further argue that virtual worlds "can be used to facilitate learning tasks that lead to improved transfer of knowledge and skills to real situations through contextualisation of learning" (p. 21).

Body A lack of non-verbal clues, including body language, gestures and facial expressions, language has been cited in studies on computer-mediated communication as negatively impacting communication (Hundsberger, 2009; Ramzan \& Ritsuko, 1998). In language acquisition, body language enhances communication by adding layers of meaning to what is spoken, which can aid comprehension as well as afford opportunities to explore mannerisms and gestures intimately linked with the target language and cultural practices (Allen, 1999; Shi \& Fan, 2010). As virtual worlds increasingly become more graphically rich and the representation of avatars becomes more lifelike (including movement such as facial expressions and gestures), the affordance of body language becomes increasingly powerful. Virtual worlds offer the opportunity for students to not only perform linguistically, but to also 'act' in culturally appropriate ways within the assumed roles in the virtual environment (Grant \& Huang, 2012).

* Note: Schwienhorst (2002) used the term 'virtual reality' (VR). However, his definition is closely aligned with the term 'virtual worlds', which became increasingly popular after 2002. Schweinhorst's descriptions of the functionality and affordances of VR are consistent with that of Second Life. 


\section{Self-efficacy beliefs}

Self-efficacy beliefs are defined as "people's judgment of their capabilities to organise and execute courses of action required to attain designated types of performances" (Bandura \& Schunk, 1981, p. 31). They are a form of self-evaluation that influences decisions individuals make, the efforts they exert, and their mastery of behaviour (Eastin \& LaRose, 2000). This theory proposes that students who believe they can successfully perform an activity will differ from students who do not. The former are likely to exert more effort, spend more time, and master the required skills earlier than the latter. In addition, Pajares and Schunk (2001) found that students who had high efficacy beliefs employed more cognitive and metacognitive strategies and persisted longer than those who did not.

Bandura's (1984, 1997, 2006) research led him to conclude that students' self-efficacy beliefs are highly predictive of their capability to accomplish academic tasks. This is supported by a number of researchers who have found that self-efficacy has a stronger effect on academic performance than other motivational beliefs (Lent, Brown \& Larkin, 1987; Pintrich \& De Groot, 1990; Pintrich \& Schunk, 2002). However, students' perceptions or experiences of previous performance play the most important role in student judgment of self-efficacy (Pintrich \& Schunk, 2002). For instance, students may form inaccurate estimations of their own efficacy in a particular task unless they have experience in that task, or in tasks they perceive as being similar. Successes and failures by themselves do not strengthen or weaken self-efficacy beliefs; rather, it is how the students interpret those experiences that have an effect (Bandura, 1997). Hence it is argued that self-efficacy is domain specific, and beliefs about efficaciousness in performing one task cannot be assumed to apply to a task in a different domain (Schunk, Pintrich \& Meece, 2007). Similarly, no amount of confidence can produce success when the necessary skills and knowledge are absent (Pajares, 2002). The implication is that while self-efficacy is considered to be predictive of student achievement, the experiential basis for students' perceptions needs to be carefully considered (Wang \& Wu, 2008).

Bandura (1997) proposed that self-efficacy beliefs are influenced in four ways, and ranked them in order of most to least influential on behaviour: enactive mastery experience, vicarious experience, verbal persuasion, and physiological and affective states. Enactive mastery is considered to be the most influential experience in shaping efficacy beliefs (Pintrich \& Schunk, 2002). Past performances serve as an indication of the extent to which one can succeed in doing a task. However, while perceived success can build a strong sense of efficacy beliefs, easy successes are also easily discouraged by failures (Bandura, 1997). According to Bandura (1997), vicarious experience also shapes efficacy beliefs because students often compare their capabilities to those of their friends, classmates or others who they feel are similar to themselves in some way. This does not suggest that students equate their efficaciousness to their friends; rather, their perception of their friends' abilities in comparison with their own perceived capabilities provides a means by which they can make judgements about their performance. Verbal persuasion refers to how self-efficacy beliefs can be influenced through the encouragement or other verbal communication of significant others, that is, people who are perceived to have mastery of a given task. However, Bandura (1997, 2004) concluded that self-efficacy beliefs, especially those founded on enactive mastery and vicarious experience, are not as easily influenced by verbal persuasion. The fourth influential factor on self-efficacy beliefs is the perception of physiological and affective 
states in relation to performance of a task. In the words of Bandura (2004), "people read their tension, anxiety, and depression as signs of personal deficiency" (p. 623). It is therefore important to consider students' physiological and affective states when designing and implementing learning activities.

There is a growing body of empirical research on the influence of self-efficacy beliefs on second language aquisition. For example, Magogwe and Oliver (2007) argued that self-efficacy beliefs relating to language learning "mediate the effect of other influences, such as aptitude or previous achievement, on subsequent performance" ( $p$. 341). In the context of an English as a second language course, Ching (2002) found that students with high self-efficacy beliefs were confident about what they could achieve, set themselves challenges and were committed to achieving them, worked harder to avoid failure, were highly resilient, and linked failure with insufficient effort or deficient knowledge and skills that they believed they were capable of acquiring. Of particular relevance to the present research is a study by Lamboy (2003), who found that an online learning environment designed to support different learning styles (e.g. visual, kinaesthetic, etc) of students learning a language can have a positive impact on their self-efficacy beliefs. This implies that the affordances of the technology (such as those described in Table 1), combined with effective instructional design, could provide an effective way to raise the self-efficacy beliefs of students.

\section{Research design}

This article reports on the findings of the second year of data collection from students enrolled in Chinese language and culture studies at Monash University in Melbourne, Australia. Specifically, it focusses on the subject Chinese 1, which is designed for learners who have never formally studied Mandarin Chinese. Aside from the use of Second Life in a series of tutorial lessons, the subject consisted of weekly lectures, seminars, speaking tutorials, and independent study based on textbooks and other online materials. The initial study was based on only one lesson in a series of oncampus lessons located in a classroom (with a computer for each student) but conducted in Second Life (see Figure 1).

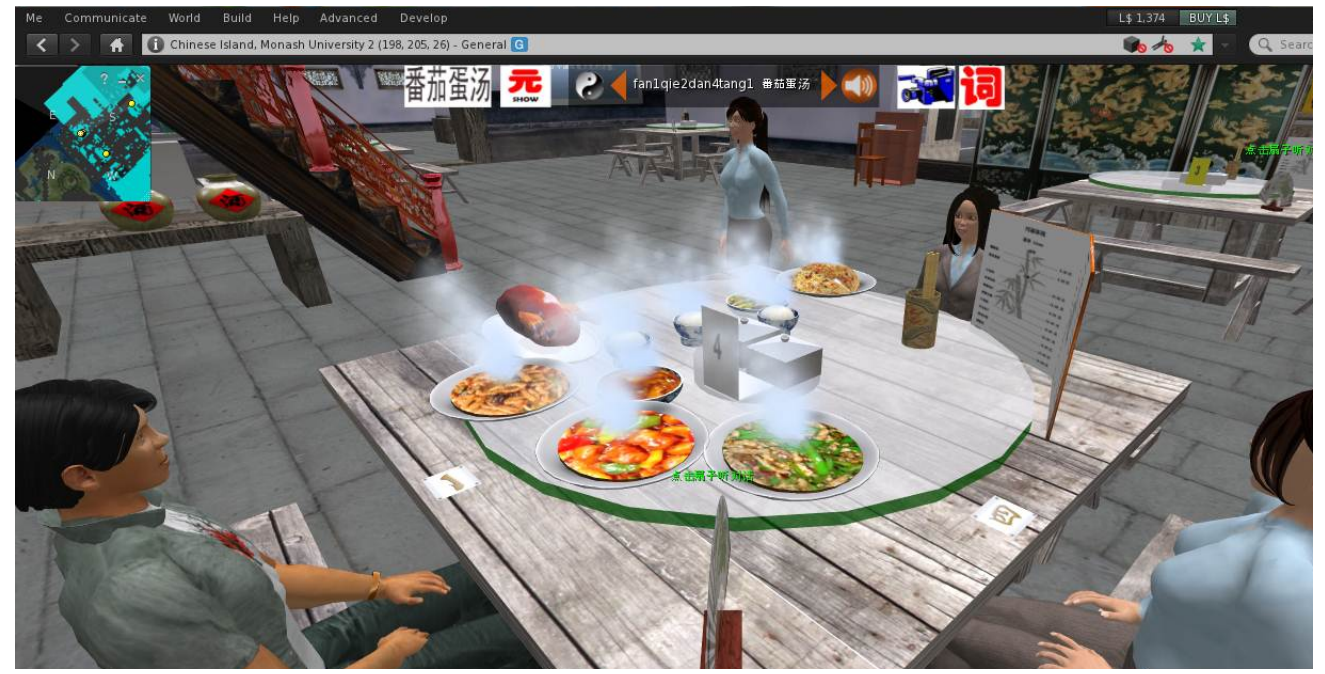

Figure 1: Chinese restaurant in Second Life 
The results of that study, discussed later, identified several problems, so a modified research design was utilised the following year. There were three key changes. First, the survey instrument was refined with modifications made to the self-efficacy scale as well as new questions added to further test issues involving domain specificity and curriculum relevance. Second, additional discriminatory data were collected to explore hypothesised explanations for variations in the impact of Second Life on self-efficacy, including prior task-related experiences (enactive mastery experience). Third, students were surveyed across two Second Life lessons a month apart in order to investigate if the impact on self-efficacy was durable across the intervening month, and if similar trends in changes to self-efficacy beliefs were observed across different scenarios. The delayed post-test was designed also for the purpose of avoiding the practice effect (i.e. the effect in which responses may change due to participants having practice at answering, or being sensitised to, the questions) because the questionnaires across the scenarios were same.

The students who chose to participate in this research were asked to complete a short questionnaire at the beginning and end of two lessons in Second Life. Although the lessons focused on different language content (e.g. vocabulary), they had similar goals in language skills (e.g. use of appropriate grammatical structures). The questionnaires ranged from 24 to 38 questions depending on the phase of study (see Table 2).

Table 2: Sequence of research activity

\begin{tabular}{|c|c|c|c|c|c|c|}
\hline \multirow{3}{*}{$\begin{array}{l}\text { Weeks } \\
(\text { of } \\
\text { research) }\end{array}$} & \multirow{3}{*}{ Class activity } & \multirow{3}{*}{$\begin{array}{l}\text { Data } \\
\text { collection } \\
\text { instrument }\end{array}$} & \multicolumn{4}{|c|}{ Focus of self-efficacy questions } \\
\hline & & & \multirow{2}{*}{$\begin{array}{l}\text { Tech. } \\
\text { abilities }\end{array}$} & \multicolumn{3}{|c|}{ Language abilities } \\
\hline & & & & $\begin{array}{c}\text { Scenario } \\
1 \\
\end{array}$ & General & $\begin{array}{c}\text { Scenario } \\
2\end{array}$ \\
\hline $\begin{array}{l}\text { Prior to } \\
\text { research }\end{array}$ & $\begin{array}{l}\text { Two lessons included Scenario } \\
1 \text { language skills. One lesson } \\
\text { devoted to learning how to use } \\
\text { Second Life. }\end{array}$ & & & & & \\
\hline \multirow[t]{2}{*}{$\begin{array}{c}\text { Week } \\
1\end{array}$} & \multirow[t]{2}{*}{$\begin{array}{l}\text { Second Life lesson: Scenario } 1 \\
\text { Ordering food in a Chinese } \\
\text { restaurant. }\end{array}$} & $\begin{array}{l}\text { Survey 1: } \\
\text { Start of } \\
\text { lesson }\end{array}$ & Pre-test & Pre-test & Pre-test & - \\
\hline & & $\begin{array}{l}\text { Survey 2: } \\
\text { End of lesson }\end{array}$ & Post-test & Post-test & Post-test & - \\
\hline $\begin{array}{c}\text { Weeks } \\
2-4\end{array}$ & $\begin{array}{l}\text { No lessons or activities using } \\
\text { Second Life. One lesson } \\
\text { included Scenario } 2 \text { skills. } \\
\text { During this time there were } \\
\text { two assessments (total } \\
\text { weighting } 10.5 \% \text { ) in which } 6 \\
\text { out of a total of } 52 \text { items } \\
\text { related to Scenario } 1 .\end{array}$ & & & & & \\
\hline \multirow[t]{2}{*}{$\begin{array}{l}\text { Week } \\
5\end{array}$} & \multirow{2}{*}{$\begin{array}{l}\text { Second Life lesson: Scenario } 2 \\
\text { Asking for directions and } \\
\text { buying grocery items in a } \\
\text { marketplace. }\end{array}$} & \begin{tabular}{|l|} 
Survey 3: \\
Start of \\
lesson
\end{tabular} & $\begin{array}{l}\text { Delayed } \\
\text { post-test }\end{array}$ & $\begin{array}{l}\text { Delayed } \\
\text { post-test }\end{array}$ & $\begin{array}{l}\text { Delayed } \\
\text { post-test }\end{array}$ & Pre-test $^{\star}$ \\
\hline & & \begin{tabular}{|l|} 
Survey 4: \\
End of lesson
\end{tabular} & \begin{tabular}{|c|} 
Delayed \\
post-test \\
$2^{*}$
\end{tabular} & - & \begin{tabular}{|c|} 
Delayed \\
post-test \\
$2^{*}$
\end{tabular} & Post-test $^{\star}$ \\
\hline \multicolumn{7}{|c|}{$\begin{array}{l}\text { *Note: The full data and analysis of these tests are not presented in this article since the primary } \\
\text { focus here is to analyse the impact and durability of self-efficacy beliefs relating to Scenario } 1 \text {. } \\
\text { However, statistical analysis was conducted and is referred to briefly in this article as } \\
\text { corroborating evidence of general trends. }\end{array}$} \\
\hline
\end{tabular}


A variety of questions provided data about age, gender, proficiency of language(s), degree of immersion and prior experience (e.g. frequency of eating at a Chinese restaurant). However, the majority of questions focussed on student self-efficacy beliefs (17 or 22 questions, depending on the phase of the study).

The self-efficacy questions were conceptually organised according to two categories: technological skills (e.g. ability to use a computer and Second Life) and language performance skills (e.g. initiate a conversation). Each of these categories was further conceptually understood to include a range of questions spanning those specifically taught in the curriculum (e.g. order a meal in a Chinese restaurant in Mandarin) and more generalised abilities not specifically covered in the curriculum (e.g. travel in China). The generalised abilities were included to permit the exploration of issues arising from the authors' previous research (Henderson et al., 2009) of domain specificity and curriculum relevance.

Implementing Bandura's (2006) advice, the self-efficacy questions were phrased so that the students were "asked to judge their operative capabilities as of now, not their potential capabilities or their expected future capabilities" (p. 312). The questions used a seven-point scale from 'no confidence' to 'highly confident'. The first iteration of this research used a five-point scale; however, the uniformly positive results suggested that, among other changes, an expanded scale might provide clearer demarcation of student variations. This is supported by Bandura (2006), who argues that a scale with more steps can provide greater sensitivity.

The four questionnaires were matched (unmatched questionnaires were excluded) and the data were tested for statistically significant variations using SPSS. Paired t-tests were done to examine the within-group variations since the participants were the same across the data collection points. To provide an indication of the effect size, et $a^{2}$ was also calculated. Additional tests were conducted, such as two-tailed Pearson correlations to test the statistical significance of students' reported level of immersion, gender, age, first language, frequency of visits to Second Life and prior experience in Chinese restaurants with their self-efficacy beliefs. Furthermore, reliability tests were performed on each test to examine the internal consistency of all items.

\section{Lesson design}

This research focuses on the impact of the first of two lessons conducted in Second Life and the durability of that impact over time. The lessons were separated by three weeks of classes in which Second Life was not used. Both Second Life lessons were specifically designed to reinforce language and culture content previously covered in the classroom and in the textbook. The design of the Scenario 1 lesson will be described in some detail here, as it is the primary focus of the data analysis.

In the Scenario 1 lesson, the activity was made authentic by asking students to work collaboratively to choose the most appropriate dishes for 'people' sitting at their table. They were informed that their table included a Muslim, a vegetarian, a diabetic, someone who did not like spicy food, someone who was allergic to seafood, and a friend from Beijing. This required students to be able to (a) understand the menu and the signs and then (b) make considered decisions among several possible alternatives, according to the description of each of the dishes and their negotiated understanding of the dietary context, including Chinese culture. In most cases there was no clear single answer. In order to complete this task in time, the students were encouraged to 
form groups, organise themselves and collaborate through the text chat facility (in Chinese). Students shared their ideas, compared their understanding of the appropriateness of the dishes, and eventually ordered the chosen dish that was brought to their table by the waiter (an avatar controlled by the tutor). While most of the communication was through the text chat facility in Second Life, students could choose to communicate in the physical classroom to give each other help, especially in terms of using the software and in learning Chinese characters and phrases that they could use in-world. Successful completion of the activity could only be achieved through reading, writing and negotiating choices in Chinese text.

The Chinese restaurant in Second Life was not intended to replicate real life but rather to evoke a sense of immersion in a Chinese setting. The building was in the shape of a traditional Chinese tea house, and Chinese-styled furniture and decorations were complemented by Chinese signs and a background recording of people talking in a real life restaurant in China. Upon arrival students, were greeted in Chinese by an automated waitress (a robot or 'bot') who also gave them a custom-designed heads-up display (HUD) that is seen at the top of Figure 1. This tool enabled the avatars to access sound files, pinyin spelling and Chinese character information for each of the dishes. This allowed students to click on a dish to hear the dish's name and see its spelling in both pinyin and Chinese characters. The students could also request more information about each of the dishes delivered, in the form of a notecard containing the main ingredients and a description of the dish.

\section{Results and discussion}

The subject had 141 students enrolled; 128 students completed at least one of the four questionnaires. Questionnaires with incomplete data and those that could not be matched were discarded. This left 81 students with complete sets of four questionnaires for analysis. The 81 students consisted of 41 females and 40 males, with all students aged 25 or younger. All of the students spoke, and to a lesser extent, had written proficiency in, two languages (English and Chinese), with $62 \%$ of them able to speak and write in three or more languages. A series of Pearson correlations were used to explore any correlations between gender, age and first language with students' selfefficacy beliefs over time. However, no statistically significant correlations were observed (all $p>.05$ ). This was consistent with the findings from the previous year. Indeed, the data from the two years initially appeared to be very similar.

In the first year of the study, a paired t-test was conducted to determine if the changes in self-efficacy beliefs between the pre and post questionnaires were statistically significant. All 12 questions relating to language indicated a strong statistical significance $(p<.05, n=100)$ in the variation over time with eta $a^{2}$ showing moderate $(>$ $0.06)$ to large $(>0.14)$ effect sizes (Cohen, 1988) that, when coupled with the increased mean difference, indicated that the lesson positively impacted those student selfefficacy beliefs relating to using the Chinese language in Chinese settings, primarily a restaurant setting. The second year of data was almost identical despite the move from a five-point to seven-point scale. When comparing the pre- and post-tests for the Scenario 1 lesson, the same 12 questions (items 3-11 and 13-15 in the current study) were found to have a statistically significant $(p<.05, n=81)$ improvement between the beginning and end of the lesson. This same strong pattern was observed for the Scenario 2 lesson, even though the content and activities were different. Accordingly, the evidence from two different cohorts (year 1: $n=100$, 1 lesson; year 2: $n=81,2$ 
lessons), strongly suggests that a single collaborative language lesson using Second Life can result in a significant increase in student self-efficacy beliefs.

A number of correlations were tested between self-efficacy beliefs and possible discriminatory data, such as technological confidence, gender, frequency of Second Life visits, first language and degree of immersion. However, the frequency of prior experience (visiting a Chinese restaurant) was the only variable that showed significant variations across the three surveys. This was also seen as consistent with self-efficacy theory since prior experience, that is, enactive mastery experience, is argued by Bandura (1997) to be the most influential factor on self-efficacy beliefs. Consequently, two groups of students were identified: Group A $(n=41$, including 20 males and 21 females), who go to a Chinese restaurant 'very often' or 'often', and Group B ( $n=40,20$ males and 20 females), who go to a Chinese restaurant 'sometimes', 'rarely' or 'never'. For convenience, this article labels Group A as having 'frequent' and Group B as having 'infrequent' experiences of Chinese restaurants. The pre-, post- and delayed post-tests were examined for within-group differences and for between-group differences. Before the examination of these differences, reliability tests were conducted respectively in each group for each test. The results found that all Cronbach's alpha coefficients were higher than $.07(.89, .95$ and .95 respectively for Group A in pre-, post- and delayed post-test; .94, .95 and .96 respectively for Group B in pre-, post- and delayed post-test), showing that the data were reliable in terms of being internally consistent.

The between-group analysis was used to compare the changes in the two groups' selfefficacy beliefs while factoring in their different starting points. A one-way analysis of variance (ANOVA) test with pre-test scores revealed that there was a significant difference $(p<.05)$ between groups in 11 language items $(3-7,11,13-17)$. The items that were not significantly different are those that are most closely linked with the curriculum taught prior to the Second Life lesson. In particular, the students had participated in, or witnessed classmates engaging in, dialogue in relation to these 4 items. Seemingly, this enactive mastery experience meant that the students, regardless of their frequency of going to a Chinese restaurant, had similar self-efficacy beliefs for these specific items. The role of the curriculum was also found to be particularly powerful in the post-test. An analysis of covariance (ANCOVA) with least significant difference (LSD) test was used to examine the difference between groups in immediate and delayed post-tests, respectively, taking pre-test scores as covariate to control for the pre-test differences. In the post-test, students' self-confidence in Group A significantly $(p<.05)$ outperformed Group B in 10 items $(3,5-6,9-13,15,17)$. The items that were not significantly different between the groups again appear to be closely associated with the curriculum of the Second Life lesson itself. That is, they were related to the language skills that students needed to perform in the lesson.

However, in the delayed post-test, the difference between groups was no longer significant on any of the language questions. In general, Group A's self-efficacy beliefs decreased over the intervening month, while Group B's continued to strengthen, resulting in the delayed post-test results of both groups to be similar (remembering that Group A's self-efficacy beliefs were initially higher than Group B's across most items in the pre-test). The results of the delayed post-test cannot be as readily explained by curriculum relevance as those of the other two tests. While all but three of the items were topics that could have potentially been represented in the assessments (see Table 2) in the intervening month, it is unlikely to have caused such a sweeping 
change since the assessments were small, and ultimately only contained six questions directly relating to these items. With the above in mind, a more detailed within-group analysis was needed to understand the variation in the delayed post-test scores.

Table 3 displays the descriptive results of pre-, post- and delayed post-tests of the two identified groups. In order to examine whether the Second Life lesson had an immediate or delayed impact on students' self-efficacy beliefs, all of the matched data were processed within each group using a paired t-test, the results of which are presented in Table 4.

Table 3: Descriptive results of group pre-, post- and delayed post-tests

\begin{tabular}{|c|c|c|c|c|c|c|c|c|c|c|c|c|c|}
\hline \multirow{3}{*}{\multicolumn{2}{|c|}{$\begin{array}{l}\text { Self-efficacy questions } \\
\begin{array}{l}\text { The degree to which you } \\
\text { feel confident to: }\end{array}\end{array}$}} & \multicolumn{6}{|c|}{$\begin{array}{c}\text { Group A: } \\
\text { Frequent Chinese restaurant } \\
\text { experiences }(n=41)\end{array}$} & \multicolumn{6}{|c|}{$\begin{array}{c}\text { Group B: } \\
\text { Infrequent Chinese restaurant } \\
\text { experiences }(n=40)\end{array}$} \\
\hline & & \multicolumn{2}{|c|}{ Pre-test } & \multicolumn{2}{|c|}{ Post-test } & \multicolumn{2}{|c|}{$\begin{array}{l}\text { Delayed } \\
\text { post-test }\end{array}$} & \multicolumn{2}{|c|}{ Pre-test } & \multicolumn{2}{|c|}{ Post-test } & \multicolumn{2}{|c|}{$\begin{array}{l}\text { Delayed } \\
\text { post-test }\end{array}$} \\
\hline & & $M$ & $S D$ & $M$ & SD & $M$ & $S D$ & $M$ & $S D$ & $M$ & $S D$ & $M$ & $S D$ \\
\hline \multirow[t]{2}{*}{ Tech. } & 1. use an online virtual world & 5.00 & 1.28 & 4.65 & 1.50 & 4.46 & 1.45 & 4.38 & 1.58 & 4.40 & 1.53 & 5.05 & 1.39 \\
\hline & 2. use a computer & 6.10 & 1.43 & 5.56 & 1.45 & 5.24 & 1.58 & 5.90 & 1.19 & 5.50 & 1.65 & 5.73 & 1.26 \\
\hline \multirow{10}{*}{$\begin{array}{l}\text { Scen- } \\
\text { ario } 1 \\
\text { lang- } \\
\text { uage }\end{array}$} & $\begin{array}{l}\text { 3. know what to do in a } \\
\text { Chinese restaurant }\end{array}$ & 4.20 & 1.33 & 4.34 & 1.04 & 3.95 & 1.28 & 3.08 & 1.33 & 3.38 & 1.29 & 3.85 & 1.12 \\
\hline & $\begin{array}{l}\text { 4. know a basic range of } \\
\text { dishes that can be ordered } \\
\text { anywhere in China }\end{array}$ & 3.54 & 1.38 & 4.15 & 1.09 & 3.73 & 1.38 & 2.68 & 1.27 & 3.43 & 1.53 & 3.80 & 1.18 \\
\hline & $\begin{array}{l}\text { 5. read a menu written in } \\
\text { Chinese in a Chinese } \\
\text { restaurant }\end{array}$ & 2.88 & 1.72 & 4.02 & 1.19 & 3.61 & 1.12 & 2.18 & 1.03 & 3.10 & 1.22 & 3.50 & 1.15 \\
\hline & $\begin{array}{l}\text { 6. } \begin{array}{l}\text { order a meal in a Chinese } \\
\text { restaurant in Mandarin }\end{array} \\
\end{array}$ & 3.02 & 1.57 & 4.20 & 1.08 & 3.59 & 1.09 & 2.25 & 1.13 & 3.25 & 1.33 & 3.65 & 1.19 \\
\hline & $\begin{array}{l}\text { 7. clarify what the main } \\
\text { ingredients are in a dish in } \\
\text { a Chinese restaurant in } \\
\text { Mandarin } \\
\end{array}$ & 3.27 & 1.63 & 3.85 & 1.22 & 3.54 & 1.16 & 2.40 & 1.28 & 3.18 & 1.36 & 3.50 & 1.18 \\
\hline & $\begin{array}{l}\text { 8. } \\
\text { to use in a Chinese } \\
\text { restaurant }\end{array}$ & 3.15 & 1.09 & 4.05 & 1.22 & 3.51 & 1.03 & 2.75 & 1.28 & 3.35 & 1.56 & 3.63 & 1.08 \\
\hline & $\begin{array}{l}\text { 9. initiate a conversation with } \\
\text { a Chinese waiter in a } \\
\text { Chinese restaurant in } \\
\text { Mandarin }\end{array}$ & 2.95 & 1.32 & 3.98 & 1.17 & 3.56 & 1.07 & 2.63 & 1.31 & 3.28 & 1.52 & 3.58 & 1.15 \\
\hline & $\begin{array}{l}\text { 10. develop a conversation } \\
\text { with a Chinese waiter in a } \\
\text { Chinese restaurant in } \\
\text { Mandarin }\end{array}$ & 2.83 & 1.20 & 3.93 & 1.17 & 3.46 & 1.12 & 2.35 & 1.15 & 3.10 & 1.35 & 3.40 & 1.22 \\
\hline & $\begin{array}{l}\text { 11. talk about eating in Chinese } \\
\text { restaurant in Mandarin }\end{array}$ & 3.02 & 1.37 & 4.00 & 1.18 & 3.51 & 1.10 & 2.38 & 1.23 & 3.05 & 1.36 & 3.55 & 1.20 \\
\hline & $\begin{array}{l}\text { 12. express your dietary prefer- } \\
\text { ences / taboos in Mandarin }\end{array}$ & 2.73 & 1.40 & 4.20 & 1.23 & 3.32 & 1.15 & 2.28 & 1.28 & 3.42 & 1.38 & 3.58 & 1.24 \\
\hline \multirow{5}{*}{$\begin{array}{l}\text { Gene- } \\
\text { ral } \\
\text { lang- } \\
\text { uage }\end{array}$} & 13. travel in China & 3.93 & 1.46 & 4.56 & 1.50 & 3.88 & 1.50 & 2.90 & 1.48 & 3.33 & 1.51 & 3.60 & 1.26 \\
\hline & 14. shop in China & 4.02 & 1.39 & 4.44 & 1.57 & 3.93 & 1.51 & 2.88 & 1.28 & 3.23 & 1.46 & 3.75 & 1.39 \\
\hline & 15. see a doctor in China & 2.80 & 1.31 & 3.51 & 1.43 & 2.93 & 1.35 & 2.00 & 1.15 & 2.38 & 1.23 & 2.68 & 1.19 \\
\hline & $\begin{array}{l}\text { 16. initiate and develop a con- } \\
\text { versation with a Chinese } \\
\text { speaker in Mandarin when } \\
\text { topic is familiar }\end{array}$ & 3.46 & 1.25 & 4.10 & 1.36 & 3.66 & 1.28 & 2.68 & 1.33 & 3.13 & 1.50 & 3.60 & 1.34 \\
\hline & $\begin{array}{l}\text { 17. initiate and develop a con- } \\
\text { versation with a Chinese } \\
\text { speaker in Mandarin when } \\
\text { topic is not familiar }\end{array}$ & 2.66 & 1.32 & 3.66 & 1.49 & 3.00 & 1.30 & 1.90 & 1.03 & 2.58 & 1.22 & 2.68 & 1.19 \\
\hline
\end{tabular}


Table 4: Within-group comparison of pre-/ post-tests and pre-/ delayed post-tests

\begin{tabular}{|c|c|c|c|c|c|c|c|c|c|c|c|c|c|}
\hline \multirow{3}{*}{\multicolumn{2}{|c|}{$\begin{array}{l}\text { Self-efficacy questions } \\
\text { The degree to which you } \\
\text { feel confident to: }\end{array}$}} & \multicolumn{6}{|c|}{$\begin{array}{c}\text { Group A: } \\
\text { Frequent Chinese restaurant } \\
\text { experiences }(n=41)\end{array}$} & \multicolumn{6}{|c|}{$\begin{array}{c}\text { Group B: } \\
\text { Infrequent Chinese restaurant } \\
\text { experiences }(n=40)\end{array}$} \\
\hline & & \multicolumn{3}{|c|}{$\begin{array}{l}\text { Paired t-test } \\
\text { between pre- } \\
\text { and post-test }\end{array}$} & \multicolumn{3}{|c|}{$\begin{array}{c}\text { Paired t-test } \\
\text { between pre- and } \\
\text { delayed post-test }\end{array}$} & \multicolumn{3}{|c|}{$\begin{array}{l}\text { Paired t-test } \\
\text { between pre- } \\
\text { and post-test }\end{array}$} & \multicolumn{3}{|c|}{$\begin{array}{c}\text { Paired t-test } \\
\text { between pre- } \\
\text { and delayed } \\
\text { post-test }\end{array}$} \\
\hline & & $t$ & $p$ & eta ${ }^{2}$ & $t$ & $p$ & $e t a^{2}$ & $t$ & $p$ & $e t a^{2}$ & $t$ & $p$ & eta ${ }^{2}$ \\
\hline \multirow[t]{2}{*}{ Tech. } & $\begin{array}{l}\text { 1. use an online virtual } \\
\text { world }\end{array}$ & -1.86 & $\begin{array}{c}r \\
.070 \\
\#\end{array}$ & $\begin{array}{c}.079 \\
++\end{array}$ & -1.92 & $\begin{array}{c}r \\
.062 \\
\#\end{array}$ & $\begin{array}{c}.084 \\
++\end{array}$ & -0.11 & .914 & .000 & 2.13 & $\stackrel{r}{.040} *$ & $\begin{array}{c}.104 \\
++\end{array}$ \\
\hline & 2. use a computer & -2.80 & .008 & $\begin{array}{l}.164 \\
+++\end{array}$ & -3.37 & .002 & $\begin{array}{l}.221 \\
+++\end{array}$ & \begin{tabular}{|l|} 
\\
\end{tabular} & $\begin{array}{c}.088 \\
\#\end{array}$ & $\begin{array}{c}.073 \\
++\end{array}$ & -0.63 & .531 & .010 \\
\hline \multirow{10}{*}{$\begin{array}{l}\text { Scen- } \\
\text { ario } 1 \\
\text { lang- } \\
\text { uage }\end{array}$} & $\begin{array}{l}\text { 3. know what to do in a } \\
\text { Chinese restaurant }\end{array}$ & 0.78 & .438 & $\begin{array}{c}.015 \\
+\end{array}$ & -0.75 & .458 & $\begin{array}{c}.014 \\
+\end{array}$ & 1.22 & .230 & $\begin{array}{c}.037 \\
+\end{array}$ & 2.83 & .007 & $\begin{array}{l}.170 \\
+++\end{array}$ \\
\hline & $\begin{array}{l}\text { 4. know a basic range of } \\
\text { dishes that can be ord- } \\
\text { ered anywhere in China }\end{array}$ & 2.80 & .008 & $\begin{array}{l}.164 \\
+++\end{array}$ & 0.60 & .553 & .009 & 3.41 & .002 & $\begin{array}{l}.230 \\
+++\end{array}$ & 4.53 & .000 & $\begin{array}{l}.345 \\
+++\end{array}$ \\
\hline & $\begin{array}{l}\text { 5. } \begin{array}{l}\text { read a m } \\
\text { Chinese } \\
\text { restaura }\end{array}\end{array}$ & 4.29 & .000 & $\begin{array}{l}.315 \\
+++\end{array}$ & 2.27 & .029 & $\begin{array}{c}.114 \\
++\end{array}$ & 4.23 & .000 & $\begin{array}{l}.315 \\
+++\end{array}$ & 6.40 & .000 & $\begin{array}{l}.512 \\
+++\end{array}$ \\
\hline & $\begin{array}{l}\text { 6. } \begin{array}{l}\text { order a } \\
\text { restaura }\end{array} \\
\end{array}$ & 5.24 & .000 & $\begin{array}{l}.407 \\
+++\end{array}$ & 1.93 & $\begin{array}{c}.060 \\
\#\end{array}$ & $\begin{array}{l}.085 \\
++\end{array}$ & 4.16 & .000 & \begin{tabular}{|l|}
.307 \\
+++
\end{tabular} & \begin{tabular}{|l|l|}
6.54 \\
\end{tabular} & .000 & $\begin{array}{l}.523 \\
+++\end{array}$ \\
\hline & $\begin{array}{l}\text { 7. clarify what the main } \\
\text { ingredients are in a dish } \\
\text { in a Chinese restaurant in } \\
\text { Mandarin } \\
\end{array}$ & 2.30 & .027 & $\begin{array}{c}.117 \\
++\end{array}$ & 0.85 & .398 & $\begin{array}{c}.018 \\
+\end{array}$ & 3.36 & .002 & $\begin{array}{l}.224 \\
+++\end{array}$ & 4.54 & .000 & $\begin{array}{l}.346 \\
+++\end{array}$ \\
\hline & \begin{tabular}{|l} 
8. \\
construct Chinese \\
sentences to use in a \\
Chinese restaurant
\end{tabular} & 4.90 & .000 & $\begin{array}{l}.375 \\
+++\end{array}$ & 1.43 & .161 & $\begin{array}{l}.049 \\
+\end{array}$ & 2.38 & .023 & $\begin{array}{l}.127 \\
++\end{array}$ & 3.81 & .000 & $\begin{array}{l}.271 \\
+++\end{array}$ \\
\hline & 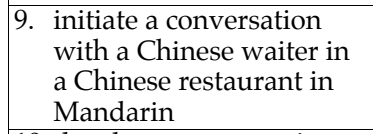 & 5.40 & .000 & $\begin{array}{l}.422 \\
+++\end{array}$ & 1.92 & $\begin{array}{c}.062 \\
\#\end{array}$ & $\begin{array}{c}.084 \\
++\end{array}$ & 2.61 & .013 & $\begin{array}{l}.149 \\
+++\end{array}$ & 4.48 & .000 & $\begin{array}{l}.340 \\
+++\end{array}$ \\
\hline & $\begin{array}{l}\text { 10. develop a conversation } \\
\text { with a Chinese waiter in } \\
\text { a Chinese restaurant in } \\
\text { Mandarin }\end{array}$ & 5.57 & .000 & $\begin{array}{l}.437 \\
+++\end{array}$ & 2.16 & .037 & $\begin{array}{c}.104 \\
++\end{array}$ & 3.50 & .001 & $\begin{array}{l}.239 \\
+++\end{array}$ & 5.03 & .000 & $\begin{array}{l}.393 \\
+++\end{array}$ \\
\hline & $\begin{array}{l}\text { 11. talk about ea } \\
\text { Chinese resta } \\
\text { Mandarin }\end{array}$ & 4.34 & .000 & $\begin{array}{l}.320 \\
+++\end{array}$ & 1.71 & $\begin{array}{c}.096 \\
\#\end{array}$ & $\begin{array}{l}.068 \\
++\end{array}$ & 3.42 & .001 & $\begin{array}{l}.231 \\
+++\end{array}$ & 5.40 & .000 & $\begin{array}{l}.428 \\
+++\end{array}$ \\
\hline & $\begin{array}{l}\text { 12. express your dietary } \\
\text { preferences / taboos in } \\
\text { Mandarin }\end{array}$ & 7.18 & .000 & $\begin{array}{l}.563 \\
+++\end{array}$ & 1.99 & $\begin{array}{c}.053 \\
\#\end{array}$ & $\begin{array}{l}.090 \\
++\end{array}$ & 5.17 & .000 & $\begin{array}{l}.407 \\
+++\end{array}$ & 5.40 & .000 & $\begin{array}{l}.428 \\
+++\end{array}$ \\
\hline \multirow{5}{*}{$\begin{array}{l}\text { Gen- } \\
\text { eral } \\
\text { lang- } \\
\text { uage }\end{array}$} & 13. travel in China & 3.22 & .003 & $\begin{array}{l}.206 \\
+++\end{array}$ & -0.13 & .895 & .000 & 2.14 & .039 & $\begin{array}{l}.105 \\
++\end{array}$ & 2.37 & .023 & $\begin{array}{c}.126 \\
++\end{array}$ \\
\hline & 14. shop in China & 2.21 & .033 & $\begin{array}{c}.109 \\
++\end{array}$ & -0.28 & .780 & .002 & 2.06 & .046 & $\begin{array}{c}.098 \\
++\end{array}$ & 3.13 & .003 & $\begin{array}{l}.201 \\
+++\end{array}$ \\
\hline & 15. see a doctor in China & 4.30 & .000 & $\begin{array}{l}.316 \\
+++\end{array}$ & 0.35 & .726 & .003 & 2.25 & .030 & $\begin{array}{c}.115 \\
++\end{array}$ & 3.04 & .004 & $\begin{array}{l}.192 \\
+++\end{array}$ \\
\hline & $\begin{array}{l}\text { 16. initiate and develop a } \\
\text { conversation with a } \\
\text { Chinese speaker in } \\
\text { Mandarin when topic is } \\
\text { familiar }\end{array}$ & 3.45 & .001 & $\begin{array}{l}.229 \\
+++\end{array}$ & 0.66 & .515 & $\begin{array}{c}.011 \\
+\end{array}$ & 2.38 & .022 & $\begin{array}{c}.127 \\
++\end{array}$ & 3.85 & .000 & $\begin{array}{l}.275 \\
+++\end{array}$ \\
\hline & $\begin{array}{l}\text { 17. initiate and develop a } \\
\text { conversation with a } \\
\text { Chinese speaker in } \\
\text { Mandarin when topic is } \\
\text { not familiar }\end{array}$ & 4.18 & .000 & $\begin{array}{l}.304 \\
+++\end{array}$ & 1.13 & .268 & $\begin{array}{c}.031 \\
+\end{array}$ & 3.54 & .001 & \begin{tabular}{|l|}
.243 \\
+++
\end{tabular} & 3.92 & .000 & $\begin{array}{l}.283 \\
+++\end{array}$ \\
\hline
\end{tabular}


The first two items are related to technological skills (i.e. confidence in using a virtual world and a computer). Table 4 indicates that the immediate experience of the Second Life lesson had a negative impact on both groups' confidence in using a computer, and to a lesser extent, in using a virtual world. This trend is probably explained by the complexity of the interface, requiring students to control the computer in unfamiliar ways, including having to initiate the Chinese character input tool, audio settings, and so on. Although the post-test results might appear anomalous (Group A had a stronger negative effect, while Group B showed an increase in confidence in using a virtual world and no significant change in confidence in using a computer) it is valuable to note that the groups were based on restaurant frequency, and as such, differences in technological confidence are unlikely to be causally related. Indeed, the between-group analysis showed no statistical difference $(p>.05)$ in the pre-test. In addition, the results of the Scenario 2 post-test (see Table 2) revealed that there was an improvement in beliefs within each group during the course of the second Second Life lesson.

The implication for educators is that despite an entire earlier lesson being devoted to relevant Second Life skills (see Table 2), students' confidence continues to be weakened as they engage with the technology in meaningful ways (i.e. for curriculum learning purposes). Consequently, while the use of introductory activities to improve technological skills is considered to be essential, it is not sufficient. The common-sense conclusion is that instructors need to design for growth of confidence over time, rather than expect students to 'get it' the first time. For example, learning activities relating to technical skills could be embedded within language learning activities and gradually increased in complexity, allowing for enactive mastery experiences.

The remaining 15 items (questions 3 to 17) asked students about their self-efficacy beliefs in language performance (ranging from skills that are closely aligned with the explicit curriculum of Scenario 1 to more general language abilities). As can be seen in Table 4, the participants in Group A significantly improved in their self-efficacy beliefs in all but one of the language items ("know what to do in a Chinese restaurant") in the immediate post-test with a large effect size $\left(p<.05\right.$, et $\left.a^{2}>0.14\right)$. However, this general improvement in self-efficacy beliefs was not maintained a month later in the delayed post-test results. The only language items in the delayed post-test to be significantly higher than the pre-test (at the level of $p<.05$ ) were their confidence in "read[ing] a menu written in Chinese" and "develop[ing] a conversation with a Chinese waiter". While these items showed a significant increase, the degree of that significance and the effect size dropped from extremely significant and large, respectively $\left(p<.001\right.$, et $a^{2}>$ $0.14)$ to significant and moderate, respectively $\left(p<.05\right.$, et $\left.a^{2}>.06\right)$. Additionally, four items $(6,9,11$ and 12) in the delayed post-test were significant at the level of $p<.10$ with moderate effect sizes $\left(e t a^{2}>.06\right)$.

The variation in significance is potentially explained by the combination of the domain-specificity principle and influence of curriculum relevance as noted in our previous study (Henderson et al., 2009), in addition to the degree of authenticity of the environment to students' 'real life' experience. For instance, all of the general language items (13 to 17) showed no statistically significant variation between the pre-test and delayed post-test for Group A. This suggests the domain-specificity principle is at work, and when compared with Group B might indicate that greater experience in interacting in the target language can refine the domain specificity, or in other words, limit the long-term impact of the Second Life experience to the specific curriculum. 
This impact, it is important to note, is also limited by the degree of authenticity, or salience of enactive mastery experiences. The lack of significant increase for items 4, 7 and 8 may be explained by incongruence with what is asked of students in the Second Life lesson and what they experience in a restaurant (e.g. in the Second Life lesson they receive a notecard when they ask for details about the dish, whereas the process of clarifying the ingredients in a restaurant is most likely conducted via speaking). It is important to note that a decrease in self-efficacy beliefs between the post-test and delayed post-test is not necessarily a decrease in ability, but could be a more realistic self-evaluation of their own abilities after enactive mastery experience or other influencing factors.

The issue of authenticity can also explain the lack of significant change in either the post-test or delayed post-test for the question "know what to do in a Chinese restaurant". This could be explained by the fact that while the Second Life lesson was ostensibly set in a Chinese-like restaurant, students were provided instructions on the steps which were noticeably different from what one would do in a real restaurant (e.g. students went to the counter and 'touched' the dishes, etc). In this case their enactive mastery experiences were so strong, and perhaps the degree of salience of the virtual restaurant was so far removed from a 'real' restaurant, that the virtual restaurant experience did not impact on their self-efficacy beliefs. In contrast, the items that significantly $(p<.10)$ increased (5 to 6 and 9 to 12$)$ were items that are language activities covered in the curriculum, reinforced in the Second Life lesson and, most importantly, would all be highly likely to be enacted in most attempts at using Chinese language in a restaurant and consequently have a high degree of authenticity. In summary, students in Group A significantly improved in their self-efficacy in almost all language items in the immediate post-survey; however, such improvement was not generally maintained in the delayed post-test a month later. Variations in self-efficacy over time are therefore hypothesised to be a result of an interaction between the principle of domain specificity, curriculum relevance and authenticity, that is, salience of the enactive mastery experiences in Second Life with that of 'real life'.

The pattern of language self-efficacy beliefs within Group B for the immediate post-test was almost identical to that of Group A (Table 4). All items, apart from "know what to do in a Chinese restaurant" had a statistically significant increase. However, unlike for Group A, there was also a statistically significant increase in the delayed post-test results for all of the self-efficacy beliefs about language performance, including the item "know what to do in a Chinese restaurant". Moreover, all of these delayed posttest items ( 3 to 17) were not only significantly improved in comparison with the pretest but also had a stronger effect size when compared with the post-test. In general, the results in Table 4 indicate that a single lesson in Second Life can significantly increase student self-efficacy beliefs, regardless of prior experience; however, the students who went to restaurants infrequently (Group B) maintained and even increased their self-efficacy beliefs not only in terms of their Scenario 1 language abilities, but for the general language skills as well.

Nevertheless, as noted by Wang and Wu (2008), the predictive value of self-efficacy beliefs is founded on the experiential basis of those beliefs. Simply because Group B reported increased confidence in their ability to, for instance, see a doctor in China, does not necessarily mean that they can actually perform to the same level as they believe they are able to. When compared with Group A, who reported more experience in Chinese restaurants (but not necessarily in using Mandarin in those 
restaurants) and who had only a limited increase in scenario language beliefs and no increase in general language beliefs, it might be suggested that Group B's sweeping improvement in self-efficacy ratings could be a result of a generalising effect in the absence of complex 'real life' enactive mastery experiences that can test their beliefs about language performance - although this has to be balanced with the knowledge that the two groups are not statistically different $(p>.05)$ from each other (betweengroup analysis) in the delayed post-test. In other words, the Second Life lesson, in conjunction with experiences over the intervening month, have strengthened Group B's confidence in such a way that none of their items are statistically different from Group A's, which have themselves been moderated from the highly positive immediate effect of the Second Life lesson to results a month later that are only marginally more positive, or are maintained, when compared to their initial (pre-test) evaluations.

\section{Conclusion}

This research lies at the nexus of three areas: virtual worlds (in this case, Second Life), instructional design for language learning (specifically Chinese) and self-efficacy beliefs. In a previous study, the impact on self-efficacy beliefs was found to be significantly positive, but it was recognised that more research was needed to better understand this impact's durability and relationship to issues such as domain specificity and prior experience (Henderson et al., 2009). As a result, a further study of 81 students over two lessons was conducted. The findings are both confirming and inconclusive: while it is clear that there was a significant impact, the reasons for that impact and variations between students call for even further research.

Overall, the evidence from two different cohorts (year 1: $n=100,1$ lesson; year 2: $n=$ 81,2 lessons) demonstrates that a single collaborative language lesson using Second Life can result in a statistically significant $(p<.05)$ increase in student self-efficacy beliefs across a range of specific and general language skills. However, after analysing the results, it was found that students with different prior experience (in this case, frequency of visiting a Chinese restaurant) varied in the durability of their language performance beliefs over time.

In terms of technological self-efficacy beliefs, the results revealed that the technological complexity of the Second Life experiences had a negative effect on students' confidence. This was only ameliorated over time with repeated experiences. While it is not surprising that practice can improve confidence, this does offer instructional designers of virtual world experiences a valuable conclusion: while the use of introductory activities (such as a skills-focused tutorial) to improve technological skills is commonly considered to be essential, it is not sufficient. Instructors need to design for activities relating to technical competency over time, and logically, as an embedded part of the curriculum, thereby facilitating growth of confidence through enactive mastery experience.

In relation to self-efficacy beliefs around language performance, a between-group analysis revealed that the groups were significantly different from each other in the pre- and post-tests. Those few self-efficacy beliefs that were not significantly different between the groups were directly aligned with the curriculum, especially when the curriculum involved enactive mastery or vicarious experience of language performance. Therefore, it appears that the degree of salience of the curriculum, in the 
form of selective language performance, results in students reporting similar beliefs about their abilities, regardless of their prior experience in visiting restaurants. The corollary is that students' self-efficacy beliefs are more varied when the language skills are not specifically represented in the curriculum. It can be concluded that the curriculum within the Second Life environment, and not just the environment itself, has a significant impact on student beliefs. This is a valuable finding and may help to dispel some critics' concerns that these Second Life teaching spaces are more playful than pedagogical (Bowers et al., 2009).

A within-group analysis revealed that the degree of prior experience, that is, enactive mastery experience of going to Chinese restaurants (but not necessarily using Mandarin), appears to be a significant factor affecting the durability of the change in self-efficacy beliefs. Importantly, students who had limited prior experience and infrequently visited Chinese restaurants were shown to have increased in their positive beliefs about their self-efficaciousness after a single lesson, and these beliefs continued to strengthen after a month. In contrast, the self-efficacy beliefs of the students who frequently visited a Chinese restaurant were shown to increase at the end of the first lesson, but then after a month reduced in strength while still being stronger than or equal to the corresponding pre-test scores. Variations in self-efficacy over time are hypothesised to be a result of an interaction between the domain specificity of the curriculum and authenticity, that is, salience of the enactive mastery experiences in Second Life with that of 'real life'. The influence of the perceived relevance of enactive mastery experiences reinforces the need for instructional design that favours selective language performance within authentic contexts.

It is interesting to note that the between-group comparison showed no statistically significant difference $(p>.05)$ on the delayed post-test, or put differently, that after a month both groups had similar self-efficacy beliefs of language performance. This means that Group B's dramatic improvement in beliefs ultimately resulted in a similar outcome to Group A's moderate increase in the curriculum-specific language performance items and their minimal change in the general language performance items. It can potentially be said that the Second Life lessons provided students who had limited 'real life' experience (Group B students) with valuable enactive mastery experiences comparable in the long term to those acquired by students in 'real life' (Group A students).

However, this tentative proposition needs to be explored further in subsequent studies that incorporate greater detail about what the students did outside of the curriculum in the intervening month. Although it is clear that the Second Life lessons had an impact on the self-efficacy beliefs of the students in both groups, further and more detailed research also needs to be carried out on the influence of authenticity (e.g. What aspects of the instructional design increase the salience of virtual world experiences to that of 'real life'?) as well as on the strength of virtual enactive mastery experiences in relation to 'real life' experiences (e.g. To what extent can an authentic experience in Second Life change beliefs based on prior 'real life' enactive mastery experiences, and indeed, how durable are those changes in the face of new enactive mastery experiences?).

\section{References}

Allen, L. Q. (1999). Functions of nonverbal communication in teaching and learning a foreign language. The French Review, 72(3), 469-480. 
Access to Virtual and Action Learning Live ONline (2010). 5th evaluation report based on_AVALON post-course survey and participants' interviews. [viewed 23 Jan 2011] http: / / avalon.humanities.manchester.ac.uk/wp-content/uploads/2010/12/Avalon_ Report_Quantitative_Qualitative_Data1.pdf

Backer, J. A. (1999). Multi-user domain object oriented (MOO) as a high school procedure for foreign language acquisition. Unpublished doctoral dissertation, Nova Southeastern University, Fort Lauderdale, FL.

Bandura, A. (1984). Recycling misconceptions of perceived self-efficacy. Cognitive Therapy and Research, 8(3), 231-255. http: / / dx.doi.org/10.1007/BF01172995

Bandura, A. (1997). Self-efficacy: The exercise of control. New York: Freeman.

Bandura, A. (2004). Swimming against the mainstream: The early years from chilly tributary to transformative mainstream. Behaviour Research and Therapy, 42(6), 613-630. http:/ / dx.doi.org/10.1016/j.brat.2004.02.001

Bandura, A. (2006). Self-efficacy beliefs of adolescents. In F. Pajares \& T. Urdan (Eds), Adolescence and education (pp. 307-335). Greenwich, CT: Information Age.

Bandura, A. \& Schunk, D. H. (1981). Cultivating competence, self-efficacy, and intrinsic interest through proximal self-motivation. Journal of Personality and Social Psychology, 41(3), 586-598. http: / / dx.doi.org/10.1037/ 0022-3514.41.3.586

Beauvois, M. (1998). Write to speak: The effects of electronic communication on the oral achievement of fourth semester French students. In J. A. Muyskens (Ed.), New ways of learning and teaching: Focus on technology and foreign language education (pp. 93-115). Boston, MA: Heinle \& Heinle.

Bell, M. W. (2008). Toward a definition of 'virtual worlds'. Journal of Virtual Worlds Research, 1(1). http: / / journals.tdl.org/jvwr/article/download/283/237

Bowers, K. W., Ragas, M. W. \& Neely, J. C. (2009). Assessing the value of virtual worlds for postsecondary instructors: A survey of innovators, early adopters and the early majority in Second Life. International Journal of Humanities and Social Sciences, 3(1), 40-50. http: / / www.waset.org/journals/ijhss/v4/v4-5-45.pdf

Carr, K. (1995). Introduction. In K. Carr \& R. England (Eds), Simulated and virtual realities: Elements of perception (pp. 1-10). London: Taylor \& Francis.

Ching, L. C. (2002). Strategy and self-regulation instruction as contributors to improving students' cognitive model in an ESL program. English for Specific Purposes, 21(3), 261-289. http: / / dx.doi.org/10.1016/S0889-4906(01)00008-4

Chun, D. \& Plass, J. L. (2000). Networked multimedia environments for second language acquisition. In M. Warschauer \& R. Kern (Eds), Network-based language teaching: Concepts and practice (pp. 151-170). Cambridge, MA: Cambridge University Press.

Clark, H. H. \& Marshall, C. T. (1981). Definite reference and mutual knowledge. In A. K. Joshi, B. L. Webber \& I. A. Sag (Eds), Elements of discourse understanding (pp. 10-63). Cambridge, UK: Cambridge University Press.

Cohen, J. (1988). Statistical power analysis for the behavioral sciences (2nd ed.). Hillsdale, NJ: Earlbaum.

Collentine, K. (2011). Learner autonomy in a task-based 3D world and production. Language Learning $\mathcal{E}$ Technology, 15(3), 50-67. http: / /lt.msu.edu/issues/october2011/ collentine.pdf 
Dalgarno, B. \& Lee, M. J. W. (2010). What are the learning affordances of 3-D virtual environments? British Journal of Educational Technology, 41(1), 10-32. http: / / dx.doi.org/10.1111/j.1467-8535.2009.01038.x

Eastin, M. \& LaRose, R. (2000). Internet self-efficacy and the psychology of the digital divide. Journal of Computer Mediated Communication, 6(1). http:/ / dx.doi.org/10.1111/ j.10836101.2000.tb00110.x

Grant, S. \& Clerehan, R. (2011). Finding the discipline: Assessing student activity in Second Life. Australasian Journal of Educational Technology, 27(5), 813-828. http: / / www.ascilite.org.au/ajet/ajet27/grant.html

Grant, S. \& Huang, H. (2012). Learning a second language in Second Life. In J. Peterson, O. Lee, T. Islam \& M. Piscioneri (Eds), Effectively implementing information communication technology in higher education in the Asia-Pacific region. Hauppauge, NY: Nova.

Hauck, M. \& Hurd, S. (2005). Exploring the link between language anxiety and learner selfmanagement in open language learning contexts. European Journal of Open, Distance and ELearning, 2005(2). http: / / www.eurodl.org/ ?p=archives\&year=2005\&halfyear=2\&article=214

Henderson, M., Huang, H., Grant, S. \& Henderson, L. (2009). Language acquisition in Second Life: Improving self-efficacy beliefs. In Same places, different spaces. Proceedings ascilite Auckland 2009 (pp. 464-474). Auckland: The University of Auckland and Auckland University of Technology. http:/ / www.ascilite.org.au/conferences/auckland09/ procs/henderson.pdf

Horwitz, E. K., Horwitz, M. B. \& Cope, J. (1986). Foreign language classroom anxiety. The Modern Language Journal, 70(2), 125-132. http:/ / dx.doi.org/10.1111/j.15404781.1986.tb05256.x

Hundsberger, S. (2009). Foreign language learning in Second Life and the implications for resource provision in academic libraries. Cambridge, UK: Cambridge University Library. http:/ / arcadiaproject.lib.cam.ac.uk/docs/second_life.pdf

Lamboy, C. L. (2003). Using technology in an English as a second language course to accommodate visual, kinaesthetic, and auditory learners to affect students' self-efficacy about learning the language. Unpublished doctoral dissertation, Nova Southeastern University, Fort Lauderdale, FL.

Lent, R. W., Brown, S. D. \& Larkin, K. C. (1987). Comparison of three theoretically derived variables in predicting career and academic behavior: Self-efficacy, interest congruence, and consequence thinking. Journal of Counseling Psychology, 34(3), 293-298. http: / / dx.doi.org/10.1037/ 0022-0167.34.3.293

Ma, R. (1996). Computer-mediated conversations as a new dimension of intercultural communication between East Asian and North American college students. In S. C. Herring (Ed.), Computer-mediated communication: Linguistic, social, and cross-cultural perspectives (pp. 173-185). Amsterdam: John Benjamins.

Magogwe, J. M. \& Oliver, R. (2007). The relationship between language learning strategies, proficiency, age and self-efficacy beliefs: A study of language learners in Botswana. System, 35(3), 338-352. http:/ / dx.doi.org/10.1016/j.system.2007.01.003

O'Rourke, B. (2005). Form-focused interaction in online tandem learning. CALICO Journal, 22(3), 433-466. https: / / www.calico.org/ memberBrowse.php?action=article\&id=144

Pajares, F. (2002). Overview of social cognitive theory and of self-efficacy. [viewed 23 Jan 2011] http: / / www.des.emory.edu/mfp/ eff.html 
Pajares, F. \& Schunk, D. H. (2001). Self-beliefs and school success: Self-efficacy, self-concept, and school achievement. In R. J. Riding \& S. G. Rayner (Eds), Self-perception (pp. 239-266). London: Ablex.

Peterson, M. (2011). Digital gaming and second language development: Japanese learners' interactions in a MMORPG. Digital Culture E Education, 3(1), 56-73. http: / / www.digital cultureandeducation.com/uncategorized/dce1048_peterson_2011_html/

Pintrich, P. R. \& De Groot, E. V. (1990). Motivational and self-regulated learning components of classroom academic performance. Journal of Educational Psychology, 82(1), 33-40. http: / / dx.doi.org/10.1037/0022-0663.82.1.33

Pintrich, P. R. \& Schunk, D. H. (2002). Motivation in education: Theory, research, and applications (2nd ed.). Englewood Cliffs, NJ: Merrill/Prentice Hall.

Ramzan, Y. \& Ritsuko, S. (1998). Computer-mediated communication in foreign language learning: A case of the students of Japanese. In Flexibility: The next wave? Proceedings ASCILITE Wollongong 1998 (pp. 585-592). University of Wollongong. http: / / www.ascilite.org.au / conferences/ wollongong98/ asc98-pdf/ ramzansaito-0066.pdf

Rankin, Y. A., McNeal, M., Shute, M. W. \& Gooch, B. (2008). User centered game design: Evaluating massive multiplayer online role playing games for second language acquisition. In S. N. Spencer (Ed.), Proceedings of Sandbox 2008: An ACM SIGGRAPH Videogame Symposium (pp. 43-49). New York: Association for Computing Machinery. http: / / dx.doi.org/10.1145/1401843.1401851

Sanchez, B. (1996). MOOving to a new frontier in language teaching. In M. Warschauer (Ed.), Telecollaboration in foreign language learning (pp. 145-164). Honolulu, HI: Second Language Teaching and Curriculum Center, University of Hawai'i.

Schunk, D. H., Pintrich, P. R. \& Meece, J. (2007). Motivation in education: Theory, research, and applications (3rd ed.). Englewood Cliffs, NJ: Prentice Hall.

Schwienhorst, K. (2002). Why virtual, why environments? Implementing virtual reality concepts in computer-assisted language learning. Simulation E Gaming, 33(2), 196-209. http: / / dx.doi.org/ 10.1177/ 1046878102332008

Shi, Y. \& Fan, S. (2010). An analysis of non-verbal behaviour in intercultural communication. The Language, Society and Culture, 31, 113-120.

http:/ / www.educ.utas.edu.au/users/tle/JOURNAL/issues/2010/31-14.pdf

Sykes, J. M. (2005). Synchronous CMC and pragmatic development: Effects of oral and written chat. CALICO Journal, 22(3), 399-431. https: / / www.calico.org/ memberBrowse.php?action=article\&id=142

Thorne, S. (2008). Mediating technologies and second language learning. In J. Coiro, M. Knobel, C. Lankshear \& D. J. Leu (Eds), Handbook of research on new literacies (pp. 415-447). Mahwah, NJ: Erlbaum.

Wang, S.-L. \& Wu, P.-Y. (2008). The role of feedback and self-efficacy on web-based learning: The social cognitive perspective. Computers $\mathcal{E}$ Education, 51(4), 1589-1598. http: / / dx.doi.org/10.1016/j.compedu.2008.03.004

Wells, G. (1981). Language, literacy and education. In G. Wells (Ed.), Learning through interaction: The study of language development (pp. 240-276). Cambridge, UK: Cambridge University Press.

Zhao, Y. \& Lai, C. (2009). MMORPGs and foreign language education. In R. E. Ferdig (Ed.), Handbook of research on effective electronic gaming in education (pp. 402-421). Hershey, PA: Information Science Reference. http:/ / dx.doi.org/10.4018/978-1-59904-808-6.ch024 
Authors: Dr Michael Henderson, Senior Lecturer in ICT in Education Faculty of Education, Monash University, Clayton, VIC 3800, Australia. Email: michael.henderson@monash.edu

Dr Hui Huang, Lecturer in Chinese Studies School of Languages, Cultures and Linguistics, Monash University Clayton, VIC 3800, Australia. Email: hui.huang@monash.edu

Scott Grant, Assistant Lecturer in Chinese Studies School of Languages, Cultures and Linguistics, Monash University Clayton, VIC 3800, Australia. Email: scott.grant@monash.edu

Associate Professor Lynette Henderson, School of Education James Cook University, Townsville, QLD 4811, Australia. Email: lynette.henderson@jcu.edu.au

Please cite as: Henderson, M., Huang, H., Grant, S. \& Henderson, L. (2012). The impact of Chinese language lessons in a virtual world on university students' selfefficacy beliefs. In M. J. W. Lee, B. Dalgarno \& H. Farley (Eds), Virtual worlds in tertiary education: An Australasian perspective. Australasian Journal of Educational Technology, 28(Special issue, 3), 400-419.

http:/ / www.ascilite.org.au/ajet/ajet28/henderson.html 